\title{
1 Carbon limitation leads to thermodynamic regulation of aerobic metabolism
}

2 Vanessa A. Garayburu-Caruso ${ }^{1}$, James C. Stegen ${ }^{1}$, Hyun-Seob Song ${ }^{1,2}$, Lupita Renteria ${ }^{1}$,

3 Jaqueline Wells ${ }^{1,3}$, Whitney Garcia ${ }^{1}$, Charles T. Resch ${ }^{1}$, Amy Goldman $^{1}$, Rosalie Chu ${ }^{4}$, Jason

4 Toyoda $^{4}$, Emily B. Graham ${ }^{1 *}$

5

$6 \quad{ }^{1}$ Pacific Northwest National Laboratory, Richland WA 99352, USA

$7 \quad{ }^{2}$ University of Nebraska-Lincoln, Lincoln NE 68588, USA

$8{ }^{3}$ Oregon State University, Corvallis, OR 97331, USA

$9 \quad{ }^{4}$ Environmental Molecular Sciences Laboratory, Richland WA 99352, USA

$10 *$ *orrespondence: emily.graham@pnnl.gov; 509-372-6049

11

12 


\section{Abstract}

14 Organic matter $(\mathrm{OM})$ metabolism in freshwater ecosystems is a critical source of uncertainty in

15 global biogeochemical cycles, yet aquatic OM cycling remains poorly understood. Here, we

16 present the first work to explicitly test OM thermodynamics as a key regulator of aerobic

17 respiration, challenging long-held beliefs that organic carbon and oxygen concentrations are the

18 primary determinants of respiration rates. We pair controlled microcosm experiments with

19 ultrahigh-resolution OM characterization to demonstrate a clear relationship between OM

20 thermodynamic favorability and aerobic respiration under carbon limitation. We also

21 demonstrate a shift in the regulation of aerobic respiration from OM thermodynamics to nitrogen

22 content when carbon is in excess, highlighting a central role for OM thermodynamics in aquatic

23 biogeochemical cycling particularly in carbon-limited ecosystems. Our work therefore

24 illuminates a structural gap in aquatic biogeochemical models and presents a new paradigm in

25 which OM thermodynamics and nitrogen content interactively govern aerobic respiration. 
28 Metabolism of organic matter (OM) in freshwater ecosystems plays a large role in global

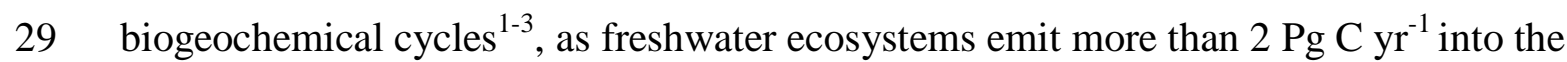

30 atmosphere ${ }^{4,5}$. These emissions are largely dominated by contributions from river corridors ${ }^{1,5,6}$,

31 and within the river corridor, areas of groundwater-surface water mixing (hyporheic zones) have

32 a disproportionate impact on aerobic respiration ${ }^{7-9}$. Recent field observations have suggested that

33 OM chemistry, and in particular OM thermodynamics, are key to predicting aerobic respiration

34 in hyporheic zones ${ }^{10-12}$. If supported, these observations challenge a widespread paradigm that

35 organic carbon and oxygen concentrations are the primary determinants of aerobic respiration

36 rates and highlight a key source of model uncertainty. Yet, no work has provided direct evidence

37 for OM thermodynamics as a regulator of aerobic respiration in a controlled laboratory

38 environment. Demonstrating this behavior would identify mechanisms that drive field-based

39 phenomena and would enable key properties of OM to be represented in predictive models,

40 thereby contributing to reducing the uncertainty in modeling river corridor biogeochemical

$41 \quad$ cycling $^{13,14}$.

42 We use highly controlled aerobic microcosms, non-invasive dissolved oxygen consumption

43 rates, and ultrahigh-resolution OM characterization to investigate the role of OM chemistry in

44 determining aerobic respiration in hyporheic zone sediments. Based on field observations ${ }^{10-12}$,

45 we hypothesized that OM chemistry, including thermodynamic favorability and nitrogen $(\mathrm{N})$

46 content, would regulate aerobic respiration. Historically, investigations of thermodynamic

47 constraints on microbial metabolism have primarily focused on oxidation-reduction reactions

48 that are controlled by the availability of various terminal electron acceptors (e.g., oxygen, nitrate,

49 sulfate $)^{15-17}$. Theory indicates that respiration under aerobic conditions is governed by rate

50 kinetics, while thermodynamic regulation has no influence. This expectation is based on the 
51 premise that using oxygen as the terminal electron acceptor provides sufficient energy for ATP

52 generation regardless of thermodynamic properties of the electron donor ${ }^{18,19}$. Consequently, the

53 role of OM thermodynamics in microbial metabolism has been mainly explored under anaerobic

54 conditions $^{20-23}$. However, OM chemistry has recently emerged as a possible regulator of aerobic

55 metabolism based on correlative field-based observation. These studies have suggested that OM

56 thermodynamics interact with $\mathrm{N}$ content and carbon concentration to influence aerobic

57 respiration ${ }^{10-12}$. Here, we present the first work to explicitly test OM thermodynamics as a key

58 regulator of aerobic respiration and demonstrate a clear relationship between OM

59 thermodynamic favorability and aerobic respiration under carbon limitation, thus challenging

60 long-held beliefs that respiration rates are govern solely by kinetics.

\section{Thermodynamic regulation of aerobic respiration}

62 To test the role $\mathrm{OM}$ chemistry as a key regulator of aerobic metabolism, we incubated sediments

63 with thermodynamically distinct N-bearing or N-free OM treatments at concentrations

64 commonly observed in freshwater systems (from 0.3 to $9 \mathrm{mg} \mathrm{C} \mathrm{L}^{-1}$, Supplementary Table

$651)^{12,24,25}$. We inferred carbon limitation at low treatment concentrations $\left(<3 \mathrm{mg} \mathrm{C} \mathrm{L}^{-1}\right)$ because

66 sediments were collected from a low carbon area $(\% \mathrm{C}<0.6$ as previously discussed in Graham

67 et al. ${ }^{11}$ ) with observed $\mathrm{C}: \mathrm{N}<5^{11}$ which is typically associated with carbon limitation ${ }^{26,27}$. In

68 addition, sediments were pre-processed prior to incubation until dissolved organic carbon

69 concentrations were below instrument detection (see Methods and Supplementary Fig. 1).

70 Moreover, aerobic respiration increased with treatment concentration from 0.3 to $3 \mathrm{mg} \mathrm{C} \mathrm{L}^{-1}$ and

71 stabilized between 3 and $9 \mathrm{mg} \mathrm{C} \mathrm{L}^{-1}$, indicating that additional carbon only stimulated respiration

72 when $3 \mathrm{mg} \mathrm{C} \mathrm{L}^{-1}$ or less was amended (Fig. 1a, $p=0.005 \& p=0.43$ ). 
74 We provide direct evidence for OM thermodynamics in controlling aerobic respiration by

75 demonstrating that thermodynamically-favorable OM supported enhanced respiration in

76 microcosms under carbon limitation. We use the mean Gibbs free energy of the half reaction of

77 organic carbon oxidation under standard conditions $\left(\overline{\Delta \mathrm{G}^{\circ} \mathrm{Cox}}\right)$ as a proxy for thermodynamic

78 favorability throughout this paper, as per LaRowe and Van Cappellen ${ }^{28}$, Graham et al. ${ }^{11}$, and

79 Stegen et al. ${ }^{12}$. Aerobic respiration was negatively correlated with $\overline{\Delta \mathrm{G}^{\circ} \text { Cox }}$ when OM was

80 amended at low concentrations (Fig. 1b-c $0.3 \mathrm{mg} \mathrm{C} \mathrm{L}^{-1} \mathrm{R}^{2}=0.23 p=0.03,3 \mathrm{mg} \mathrm{C} \mathrm{L} \mathrm{R}^{2}=0.34$

$81 p=0.007)$.

82 While our results support previous field observations that emphasize the role of OM

83 thermodynamics in predicting aerobic respiration ${ }^{11,12}$, we uniquely underscore the central role for

84 OM thermodynamics in the metabolism of carbon-limited ecosystems using highly controlled

85 laboratory experiments. A field study by Graham et al. ${ }^{11}$ showed that thermodynamically

86 favorable OM was preferentially metabolized in sediments across a vegetation gradient.

87 Similarly, Stegen et al. ${ }^{12}$ highlighted the importance of OM thermodynamics in regulating

88 aerobic respiration within hyporheic zones. While the previous works are based on correlative

89 observations, our controlled laboratory microcosms allowed us to clearly demonstrate

90 thermodynamic regulation of aerobic metabolism and define the conditions under which OM

91 thermodynamics provide an avenue for improving aquatic biogeochemical models.

92 Specifically, we reveal a dependency of thermodynamic OM regulation on organic carbon

93 concentration, as sediments putatively not experiencing carbon limitation had no evidence of

94 thermodynamic constraints on aerobic respiration (Fig. $1 \mathrm{~d}, 9 \mathrm{mg} \mathrm{C} \mathrm{L}^{-1} p=0.71$ ). Low molecular

95 weight carbon compounds, such as the amino and organic acids used for treatments in this

96 experiment (see Methods), are highly bioavailable to microorganisms which have direct uptake 
97 pathways for these molecules ${ }^{29-31}$ in contrast to polymeric OM in sediments that requires the

98 production of extracellular enzymes ${ }^{32,33}$. Thus, we hypothesize that excess low molecular weight

99 and highly bioavailable OM diminishes the benefits of thermodynamic preference in metabolism,

100 because the low microbial cost of direct uptake outweighs the energy benefit gained from

101 selective carbon metabolism.

102 Pathways of OM metabolism vary with thermodynamic control of aerobic respiration

103 We underscore a need for improved model structures for predicting aerobic respiration, as we

104 observed different metabolic processes between carbon-limited and carbon-replete environments.

105 To investigate metabolic processes involved in aerobic respiration, we calculated inferred

106 biochemical transformations in ultrahigh-resolution OM profiles following procedures described

107 previously ${ }^{10-12,34-36}$. This method relies on the mass accuracy of Fourier transform ion cyclotron

108 resonance mass spectrometry (FTICR-MS) and produces a count of the number of times a

109 specific molecule (e.g., glucose, valine, glutamine, etc.) is putatively gained or lost in reactions

110 (see Methods).

111 While previous work has suggested both thermodynamic and N-related regulation of aerobic

112 respiration ${ }^{10-12}$, we postulate a carbon limitation threshold beyond which thermodynamic

113 controls do not persist. Our data suggest that beyond this threshold (i.e., in the absence of carbon

114 limitation), aerobic respiration is coupled to organic $\mathrm{N}$ metabolism. We found no differences in

115 OM chemistry (Supplementary Fig. 2a-b, all $p>0.05)$, respiration rates $(p=0.11$ at $0.3 \mathrm{mg} \mathrm{C}$

$116 \mathrm{~L}^{-1}$ and $p=0.24$ at $3 \mathrm{mg} \mathrm{C} \mathrm{L}^{-1}$ ) or biochemical transformations (Fig. 2a-b, $0.3 \mathrm{mg} \mathrm{C} \mathrm{L}^{-1} p=$

$1170.67,3 \mathrm{mg} \mathrm{C} \mathrm{L}^{-1} p=0.91$ ) across microcosms with $\mathrm{N}$-bearing vs. N-free OM amended when

118 respiration was thermodynamically-controlled (i.e., in carbon limited conditions). However,

119 respiration in carbon-replete microcosms $\left(9 \mathrm{mg} \mathrm{C} \mathrm{L}^{-1}\right)$ increased with the addition of organic $\mathrm{N}$ 
120 relative to $\mathrm{N}$-free $\mathrm{OM}$, and pathways of OM metabolism varied between treatments with or

121 without added organic $\mathrm{N}$ (Fig. 2c-d, $p=0.04, p=0.04$ ). Biochemical transformations in

122 microcosms receiving $9 \mathrm{mg} \mathrm{C} \mathrm{L}^{-1}$ more frequently involved $\mathrm{N}$ when organic $\mathrm{N}$ was added to

123 microcosms (Supplementary Fig. 3, $p=0.02$ ). Additionally, we provide evidence that N-

124 enriched molecules are preferably consumed in natural environments with surplus carbon.

125 Bioavailable organic $\mathrm{N}$ addition increased the relative abundance of more complex protein-like

$126 \mathrm{OM}$, suggesting the preservation of sediment-bound $\mathrm{OM}$ containing $\mathrm{N}$ in the presence of more

127 accessible $\mathrm{N}$ sources (Supplementary Fig. 2c, $p<0.01$ ). Together, these results are consistent

128 with N-mining observed previously in this system, whereby OM is oxidized for microbial

129 acquisition of $\mathrm{N}^{10,37}$.

130 More broadly, we highlight that when organic carbon is in excess, there is a dependency of

131 aerobic respiration on specific nutrient limitations rather than on OM thermodynamics.

132 Therefore, OM thermodynamics appear to be most informative of aquatic biogeochemistry

133 within carbon-limited ecosystems, while $\mathrm{N}$ availability governs aerobic respiration at higher

134 carbon to nitrogen ratios $(\mathrm{C}: \mathrm{N})$. While $\mathrm{N}$-dependent aerobic respiration at high $\mathrm{C}: \mathrm{N}$ is consistent

135 with nutrient limitations observed in variety of systems ${ }^{38,39}$, thermodynamic regulation at low

$136 \mathrm{C}: \mathrm{N}$ ratios challenges the widespread notion that organic carbon and oxygen concentrations are

137 the main variables driving respiration.

\section{Enhancing model predictions with a new paradigm of aquatic biogeochemical cycling}

139 While many processed-based models represent biogeochemical cycles, most model structures

140 contain only a few lumped carbon pools that do not fully represent the complexity of natural OM

141 sources $^{20,21}$. Organic matter cycling is typically modeled following Michaelis-Menten kinetics,

142 with OM separated into particulate or dissolved pools ${ }^{40}$. In some cases, these pools are further 
143 categorized by environmental properties or bioavailability, and each subpool is assigned a fixed

144 mineralization rate $\mathrm{r}^{20,40-42}$. These traditional approaches do not address OM chemistry because

145 commonly used bulk characterization techniques do not provide sufficient molecular detail, and

146 because representing individual OM molecules in a given ecosystem is computationally

147 unfeasible. Our work demonstrates that processes associated with OM thermodynamics and N

148 content strongly influence aerobic respiration — and, in turn, biogeochemical reaction networks-

149 thus providing a link between OM chemistry and biogeochemical rates that will help inform and

150 parameterize new and existing models.

151 We therefore propose a new conceptual model with direct avenues for model incorporation in

152 which OM thermodynamics regulates aerobic respiration until organic carbon concentrations are

153 sufficient to induce nutrient limitations (Fig. 3). We suggest that a combination of organic carbon

154 concentration and thermodynamic limitation governs aerobic respiration in sediments with low

155 carbon to nutrient ratios. In contrast, nutrient limitation regulates respiration when bioavailable

156 carbon is in excess, and in this scenario, organic $\mathrm{N}$ may be a key constraint on respiration. This is

157 consistent with previous reports of a strong role from organic $\mathrm{N}$ cycling in hyporheic zones and

158 freshwater systems ${ }^{10,12,43,44}$. While our work represents a single system, our conceptual model is

159 meant to provide proof-of-concept for more spatially extensive studies that will allow broader

160 transferability.

161 To our knowledge, this is the first work to provide direct evidence for OM thermodynamics as a

162 regulator of aerobic respiration in a controlled laboratory environment and highlights a key gap

163 in current mechanistic understanding of OM cycling. In order to improve model accuracy, we

164 reveal a need to explicitly represent the interactions between OM thermodynamics, nutrient

165 limitations, and organic carbon concentration in process-based models of aquatic carbon cycling. 
166 Our results constrain the environments under which specific chemical attributes of OM are

167 valuable for rate predictions and provide guidance on the data types that are needed to accurately

168 represent hyporheic zone biogeochemistry. These processes cannot be represented by lumped

169 OM pools informed by decades of coarse measurements, and thus we highlight the utility of

170 high-resolution technologies in models of aquatic biogeochemistry and present a new paradigm

171 in which aerobic respiration is governed by a combination of carbon concentration, OM

172 thermodynamics, and nutrient limitations.

\section{Acknowledgements}

174 This research was supported by the U.S. Department of Energy (DOE), Office of Biological and

175 Environmental Research (BER), as part of Subsurface Biogeochemical Research Program's

176 Scientific Focus Area (SFA) at the Pacific Northwest National Laboratory (PNNL). Data were

177 generated under EMSL user proposal 51180. A portion of the research was performed at

178 Environmental Molecular Science Laboratory User Facility. PNNL is operated for DOE by

179 Battelle under contract DE-AC06-76RLO 1830.

\section{Author Contributions}

181 V.G.C., E.B.G, H.S.S. and J.C.S., conceptualized the study; V.G.C., L.R., J.W., W.G, and A.G.,

182 carried out the study; C.T.R., R.C. and J.T. conducted instrumental analyses; V.G.C. and E.B.G

183 drafted the manuscript and all authors contributed to the writing.

\section{Competing interests}

185 The authors declare no competing financial interests. 


\section{Materials and methods}

\section{Study site and sediment collection}

188 This study was conducted using sediments from the Columbia River hyporheic zone within the

189 Hanford Site 300 Area (approximately $46^{\circ} 22^{\prime} 15.80^{\prime \prime} \mathrm{N}, 119^{\circ} 8516^{\prime} 31.52^{\prime \prime} \mathrm{W}$ ) in eastern

190 Washington, USA ${ }^{10,11,45}$. Hyporheic zone sediments were collected in April 2018 at five

191 locations, separated by $\sim 2 \mathrm{~m}$ (depth: $\sim 30 \mathrm{~cm}$ ). Sediments were sieved in the field to $<2 \mathrm{~mm}$,

192 homogenized, and kept on ice until same-day laboratory processing. We performed sequential

193 organic carbon extractions with synthetic river water (see Supplementary Methods for

194 composition) prior to incubations to minimize the influence of carbon mobilized from sediments

195 during field sampling. Details regarding pre-processing step are provided in the Supplementary

196 Methods.

\section{Laboratory Microcosms}

198 We used a total of 85 microcosms in a full factorial design (a) four chemically distinct OM

199 amendments at three concentrations, (b) four autoclaved controls (heat kills), and (c) one

200 synthetic water control, each treatment with five replicates. Incubations were performed over the

201 course of 5 days, where each day we incubated 17 bioreactors (i.e., 1 replicate treatment per day,

202 see design in Supplementary Table 1). On the day prior to the experiment, $10 \mathrm{~g}$ of pre-processed

203 sediments were removed from $4^{\circ} \mathrm{C}$ storage and subsampled into $20 \mathrm{~mL}$ borosilicate glass vials.

204 Vials were left in the dark at ambient laboratory temperature for $8 \mathrm{~h}$ before incubation to

205 acclimate to room temperature.

206 To initiate microcosms, $18 \mathrm{~mL}$ of treatment solution was added to vials containing sediment,

207 leaving < $1 \mathrm{~mL}$ headspace. Treatment solution consisted of synthetic river water and the specific 
208 OM compound at the desired concentration (Supplementary Table 1). Nitrate and phosphate

209 were added to the synthetic river water to provide sufficient nutrients for the duration of the

210 experiment - nitrate concentration matched ambient groundwater while phosphate concentration

211 matched the Redfield ratio relative to groundwater N (16N:P). We added the following 4 types of

212 OM because their thermodynamic properties encompassed the extremes experienced by the

213 surface and the groundwater in situ $^{12}$ and were either N-bearing or N-free: Lysine (Gibbs free

214 energy of the half reaction of organic carbon under standard conditions, $\Delta \mathrm{G}^{\circ} \mathrm{Cox}=79.40 \mathrm{~kJ}(\mathrm{~mol}$

$215 \mathrm{C})^{-1}$, N-bearing), Serine $\left(\Delta \mathrm{G}^{\circ}{ }_{\mathrm{Cox}}=41.21 \mathrm{~kJ}(\mathrm{~mol} \mathrm{C})^{-1}\right.$, N-bearing $)$, Propionate $\left(\Delta \mathrm{G}^{\circ}{ }_{\mathrm{Cox}}=79.40 \mathrm{~kJ}\right.$

$216(\mathrm{~mol} \mathrm{C})^{-1}, \mathrm{~N}$-free $)$, and Ascorbate $\left(\Delta \mathrm{G}^{\circ} \mathrm{Cox}=41.21 \mathrm{~kJ}(\mathrm{~mol} \mathrm{C})^{-1}, \mathrm{~N}\right.$-free $)$. The vials were placed

217 horizontally on a shaker at $250 \mathrm{rpm}$ in the dark at $21 \pm 1^{\circ} \mathrm{C}$ for the duration of the experiment,

218 except during dissolved oxygen measurements.

\section{Respiration rates}

220 Dissolved oxygen (DO) concentration $\left(\mu \mathrm{mol} \mathrm{L}^{-1}\right)$ was measured in each microcosm every hour

221 for $6 \mathrm{~h}$ using $0.5 \mathrm{~cm}$ diameter factory-calibrated oxygen sensors and an oxygen optical meter

222 (Fibox 3; PreSens GmbH, Regensburg, Germany). The DO measurements were automatically

223 corrected for temperature and the data were recorded using PST3v602 software (PreSens

$224 \mathrm{GmbH})$. Respiration rates were calculated as the slope of the linear regression between DO

225 concentration and incubation time for each microcosm (Supplementary Fig. 4-6). We infer that

226 changes in DO were driven by aerobic respiration, as DO in heat kills did not change during the

227 incubation (Supplementary Fig. 7). pH measurements were also collected using an optical meter

228 and factory calibrated $\mathrm{pH}$ sensor spots ( $\mathrm{pH}-1$ mini; PreSens $\mathrm{GmbH}$ ). $\mathrm{pH}$ values did not change

229 during the incubation (Supplementary Fig. 8). After 6 hours, microcosm contents were

230 transferred to $50 \mathrm{~mL}$ sterile polypropylene centrifuge tubes and centrifuged for $5 \mathrm{~min}$ at $3200 \mathrm{rcf}$ 
231 and $20^{\circ} \mathrm{C}$. The supernatant was filtered through a $0.22 \mu \mathrm{m}$ polyethersulfone membrane filter

232 (Millipore Sterivex, USA) frozen at $-20^{\circ} \mathrm{C}$ until further analysis.

\section{Fourier transform ion cyclotron resonance mass spectrometry (FTICR-MS)}

234 Fourier transform-ion cyclotron resonance mass spectrometer (FTICR-MS) (12 Tesla (12T)

235 Bruker SolariX, Billerica, MA) located at the Environmental Molecular Sciences Laboratory in

236 Richland, WA, was used to collect high-resolution mass spectra of the OM. Resolution was

$237220 \mathrm{~K}$ at $481.185 \mathrm{~m} / \mathrm{z}$. The FTICR-MS was outfitted with a standard electrospray ionization (ESI)

238 source, and data was acquired in negative mode with the voltage set to $+4.4 \mathrm{kV}$. Data were

239 collected with an ion accumulation time of $0.3 \mathrm{sec}$ from $98-900 \mathrm{~m} / \mathrm{z}$ at $4 \mathrm{M}$. One hundred

240 fourty-four scans were co-added. BrukerDaltonik (version 4.2) was used to convert raw spectra

241 to a list of $\mathrm{m} / \mathrm{z}$ values by applying FTMS peak picker module. Chemical formulas were then

242 assigned using in-house software following the Compound Identification Algorithm ${ }^{46-49}$, using

243 the criteria previously described by Graham et al. ${ }^{10,11}$. The chemical character of the compounds

244 identified in the FTICR-MS spectrum and their biochemical classes were evaluated using Van

245 Krevelen diagrams.

246 We calculated the $\Delta \mathrm{G}_{\text {Cox }}^{\circ}$ to evaluate relationships between aerobic respiration and OM

247 thermodynamics, as per LaRowe and Van Cappellen ${ }^{28}$. An expanded description of sample

248 preparation, instrument and FTCR-MS data processing for estimating Van Krevelen diagrams

249 and $\Delta \mathrm{G}^{\circ}$ Cox is presented in the Supplementary Methods.

\section{Identification of biochemical transformations using FTICR-MS}

251 Biochemical transformations were inferred by calculating all possible pairwise mass differences

252 within a sample's spectrum and matching differences (within $1 \square \mathrm{ppm}$ ) to a list of common 
253 biochemical transformations ${ }^{50}$. Biochemical transformations were identified following the

254 procedures described by Breitling et al. ${ }^{50}$ and previously employed by Bailey et al. ${ }^{34}$, Graham et

255 al. ${ }^{10,11}$, Moritz et al. ${ }^{36}$, Kaling et al. ${ }^{35}$, and Stegen et al. ${ }^{12}$. Briefly, pairwise mass differences

256 between all $\mathrm{m} / \mathrm{z}$ peaks in a sample were compared with a reference list of 1298 commonly

257 observed biochemical reactions of organic matter (Supplementary Table 2). For mass differences

258 matching to compounds in the reference list, we inferred the gain or loss of that compound via a

259 biochemical transformation.

260 Statistical analyses

261 All statistical analyses were completed using R (version 3.4.1). Linear regressions were used to

262 assess the relationship between respiration rates and $\overline{\Delta \mathrm{G}^{\circ} \text { Cox }}$. Differences across groups were

263 evaluated with one-sided Mann-Whitney U test. Permutational multivariate analysis of variance

264 (PERMANOVA) of Bray-Curtis distances was used to assess dissimilarities among

265 biogeochemical transformations in the "vegan" R package. PERMANOVAs were stratified by

$266 \Delta \mathrm{G}_{\text {Cox }}^{\circ}$ to account for any differences due to the thermodynamic properties of the treatment

267 solution. Biochemical transformations were visualized with non-metric multidimensional scaling

268 (NMDS). 


\section{References}

2711 Battin, T. J. et al. Biophysical controls on organic carbon fluxes in fluvial networks.

272 Nature geoscience 1, 95 (2008).

2732 Cole, J. J. et al. Plumbing the global carbon cycle: integrating inland waters into the

$274 \quad$ terrestrial carbon budget. Ecosystems 10, 172-185 (2007).

2753 Tranvik, L. J. et al. Lakes and reservoirs as regulators of carbon cycling and climate.

$276 \quad$ Limnology and Oceanography 54, 2298-2314 (2009).

2774 Sawakuchi, H. O. et al. Carbon dioxide emissions along the lower Amazon River.

$278 \quad$ Frontiers in Marine Science 4, 76 (2017).

2795 Raymond, P. A. et al. Global carbon dioxide emissions from inland waters. Nature 503,

$280 \quad 355(2013)$.

2816 Ruhala, S. S. \& Zarnetske, J. P. Using in-situ optical sensors to study dissolved organic 282 carbon dynamics of streams and watersheds: A review. Sci Total Environ 575, 713-723, 283 doi:10.1016/j.scitotenv.2016.09.113 (2017).

2847 Naegeli, M. W. \& Uehlinger, U. Contribution of the hyporheic zone to ecosystem 285 metabolism in a prealpine gravel-bed-river. Journal of the North American Benthological 286 Society 16, 794-804 (1997).

2878 Battin, T. J., Kaplan, L. A., Newbold, J. D. \& Hendricks, S. P. A mixing model analysis 288 of stream solute dynamics and the contribution of a hyporheic zone to ecosystem 289 function. Freshwater Biology 48, 995-1014 (2003).

2909 Kaplan, L. A., Wiegner, T. N., Newbold, J., Ostrom, P. H. \& Gandhi, H. Untangling the 291 complex issue of dissolved organic carbon uptake: a stable isotope approach. Freshwater 292 Biology 53, 855-864 (2008). 
29310 Graham, E. B. et al. Multi 'omics comparison reveals metabolome biochemistry, not 294 microbiome composition or gene expression, corresponds to elevated biogeochemical 295 function in the hyporheic zone. Sci Total Environ 642, 742-753,

296 doi:10.1016/j.scitotenv.2018.05.256(2018).

29711 Graham, E. B. et al. Carbon Inputs From Riparian Vegetation Limit Oxidation of 298 Physically Bound Organic Carbon Via Biochemical and Thermodynamic Processes. 299 Journal of Geophysical Research: Biogeosciences 122, 3188-3205, 300 doi:10.1002/2017jg003967 (2017).

30112 Stegen, J. C. et al. Influences of organic carbon speciation on hyporheic corridor 302 biogeochemistry and microbial ecology. Nat Commun 9, 585, doi:10.1038/s41467-018$303 \quad$ 02922-9(2018).

30413 Regnier, P. et al. Anthropogenic perturbation of the carbon fluxes from land to ocean. $305 \quad$ Nature geoscience 6, 597 (2013).

30614 Butman, D. \& Raymond, P. A. Significant efflux of carbon dioxide from streams and 307 rivers in the United States. Nature Geoscience 4, 839 (2011).

30815 Hedin, L. O. et al. Thermodynamic constraints on nitrogen transformations and other 309 biogeochemical processes at soil-stream interfaces Ecology 79, 684-703, 310 doi:10.1890/0012-9658(1998)079[0684:tconao]2.0.co;2 (1998).

31116 McClain, M. E. et al. Biogeochemical hot spots and hot moments at the interface of 312 terrestrial and aquatic ecosystems. Ecosystems 6, 301-312 (2003).

31317 Craig, L., Bahr, J. M. \& Roden, E. E. Localized zones of denitrification in a floodplain 314 aquifer in southern Wisconsin, USA. Hydrogeology Journal 18, 1867-1879, 315 doi:10.1007/s10040-010-0665-2 (2010). 
31618 Jin, Q. \& Bethke, C. M. A new rate law describing microbial respiration. Appl. Environ.

317 Microbiol. 69, 2340-2348 (2003).

31819 Keiluweit, M., Nico, P. S., Kleber, M. \& Fendorf, S. Are oxygen limitations under

319 recognized regulators of organic carbon turnover in upland soils? Biogeochemistry $\mathbf{1 2 7}$,

320 157-171, doi:10.1007/s10533-015-0180-6 (2016).

32120 Burd, A. B. et al. Terrestrial and marine perspectives on modeling organic matter

322 degradation pathways. Global change biology 22, 121-136 (2016).

32321 Li, L. et al. Expanding the role of reactive transport models in critical zone processes.

324 Earth-science reviews 165, 280-301 (2017).

32522 Boye, K. et al. Thermodynamically controlled preservation of organic carbon in

326 floodplains. Nature Geoscience 10, 415-419, doi:10.1038/ngeo2940 (2017).

32723 Pracht, L. E., Tfaily, M. M., Ardissono, R. J. \& Neumann, R. B. Molecular

328 characterization of organic matter mobilized from Bangladeshi aquifer sediment: tracking

329 carbon compositional change during microbial utilization. Biogeosciences 15, 1733-1747,

330 doi:10.5194/bg-15-1733-2018 (2018).

33124 Musolff, A. et al. Spatio-temporal controls of dissolved organic carbon stream water

332 concentrations. Journal of Hydrology 566, 205-215, doi:10.1016/j.jhydrol.2018.09.011

333 (2018).

33425 Yang, Q., Zhang, X., Xu, X. \& Asrar, G. R. An analysis of terrestrial and aquatic

335 environmental controls of riverine dissolved organic carbon in the conterminous United

$336 \quad$ States. Water 9, 383 (2017).

33726 Egli, T., Lendenmann, U. \& Snozzi, M. Kinetics of microbial growth with mixtures of

338 carbon sources. Antonie van Leeuwenhoek 63, 289-298 (1993). 
33927 Zinn, M., Witholt, B. \& Egli, T. Dual nutrient limited growth: models, experimental

340 observations, and applications. Journal of biotechnology 113, 263-279 (2004).

34128 LaRowe, D. E. \& Van Cappellen, P. Degradation of natural organic matter: A

342 thermodynamic analysis. Geochimica et Cosmochimica Acta 75, 2030-2042,

343 doi:10.1016/j.gca.2011.01.020(2011).

34429 Berggren, M. \& del Giorgio, P. A. Distinct patterns of microbial metabolism associated

345 to riverine dissolved organic carbon of different source and quality. Journal of

346 Geophysical Research: Biogeosciences 120, 989-999, doi:10.1002/2015jg002963 (2015).

34730 Sundh, I. Biochemical composition of dissolved organic carbon derived from

348 phytoplankton and used by heterotrophic bacteria. Appl. Environ. Microbiol. 58, 2938-

$3492947(1992)$.

$35031 \quad$ Rosenstock, B. \& Simon, M. Use of dissolved combined and free amino acids by

$351 \quad$ planktonic bacteria in Lake Constance. Limnology and Oceanography 38, 1521-1531

352 (1993).

35332 Khatoon, H., Solanki, P., Narayan, M., Tewari, L. \& Rai, J. Role of microbes in organic

354 carbon decomposition and maintenance of soil ecosystem. (2017).

35533 Arnosti, C. et al. Extracellular enzymes in terrestrial, freshwater, and marine

356 environments: perspectives on system variability and common research needs.

357 Biogeochemistry 117, 5-21 (2014).

35834 Bailey, V. L., Smith, A., Tfaily, M., Fansler, S. J. \& Bond-Lamberty, B. Differences in

359 soluble organic carbon chemistry in pore waters sampled from different pore size

360 domains. Soil Biology and Biochemistry 107, 133-143 (2017). 
36135 Kaling, M. et al. Mycorrhiza-triggered transcriptomic and metabolomic networks

362 impinge on herbivore fitness. Plant physiology 176, 2639-2656 (2018).

36336 Moritz, F., Kaling, M., Schnitzler, J. P. \& Schmitt-Kopplin, P. Characterization of poplar

364 metabotypes via mass difference enrichment analysis. Plant Cell Environ 40, 1057-1073,

365 doi:10.1111/pce.12878 (2017).

36637 Moorhead, D. L. \& Sinsabaugh, R. L. A theoretical model of litter decay and microbial

367 interaction. Ecological Monographs 76, 151-174 (2006).

36838 Treseder, K. K. Nitrogen additions and microbial biomass: A meta $\square$ analysis of

369 ecosystem studies. Ecology letters 11, 1111-1120 (2008).

37039 Vitousek, P. M. \& Howarth, R. W. Nitrogen limitation on land and in the sea: how can it

$371 \quad$ occur? Biogeochemistry 13, 87-115 (1991).

$37240 \quad$ Wang, G., Post, W. M. \& Mayes, M. A. Development of microbial $\square$ enzyme $\square$ mediated

373 decomposition model parameters through steady $\square$ state and dynamic analyses. Ecological

$374 \quad$ Applications 23, 255-272 (2013).

37541 Sulman, B. N., Phillips, R. P., Oishi, A. C., Shevliakova, E. \& Pacala, S. W. Microbe-

376 driven turnover offsets mineral-mediated storage of soil carbon under elevated CO 2.

$377 \quad$ Nature Climate Change 4, 1099 (2014).

37842 Vachon, D., Prairie, Y. T., Guillemette, F. \& Del Giorgio, P. A. Modeling allochthonous

379 dissolved organic carbon mineralization under variable hydrologic regimes in boreal

$380 \quad$ lakes. Ecosystems 20, 781-795 (2017).

$38143 \quad$ Brookshire, E. N. J., Valett, H. M., Thomas, S. A. \& Webster, J. R. Coupled cycling of 382 dissolved organic nitrogen and carbon in a forest stream. Ecology 86, 2487-2496 (2005). 
38344 Bernal, S., Lupon, A., Catalán, N., Castelar, S. \& Martí, E. Decoupling of dissolved

$384 \quad$ organic matter patterns between stream and riparian groundwater in a headwater forested

385 catchment. Hydrology and Earth System Sciences 22, 1897-1910, doi:10.5194/hess-22-

$386 \quad$ 1897-2018 (2018).

38745 Goldman, A. E. et al. Biogeochemical cycling at the aquatic-terrestrial interface is linked 388 to parafluvial hyporheic zone inundation history. Biogeosciences 14, 4229-4241, 389 doi:10.5194/bg-14-4229-2017 (2017).

39046 Kujawinski, E. B. \& Behn, M. D. Automated analysis of electrospray ionization Fourier 391 transform ion cyclotron resonance mass spectra of natural organic matter. Analytical $392 \quad$ Chemistry 78, 4363-4373 (2006).

39347 Minor, E. C., Steinbring, C. J., Longnecker, K. \& Kujawinski, E. B. Characterization of 394 dissolved organic matter in Lake Superior and its watershed using ultrahigh resolution 395 mass spectrometry. Organic geochemistry 43, 1-11 (2012).

39648 Tfaily, M. M. et al. Sequential extraction protocol for organic matter from soils and 397 sediments using high resolution mass spectrometry. Analytica chimica acta 972, 54-61 398 (2017).

39949 Tolić, N. et al. Formularity: software for automated formula assignment of natural and $400 \quad$ other organic matter from ultrahigh-resolution mass spectra. Analytical chemistry 89, $401 \quad$ 12659-12665 (2017).

$40250 \quad$ Breitling, R., Ritchie, S., Goodenowe, D., Stewart, M. L. \& Barrett, M. P. Ab initio 403 prediction of metabolic networks using Fourier transform mass spectrometry data. 404 Metabolomics 2, 155-164, doi:10.1007/s11306-006-0029-z (2006). 

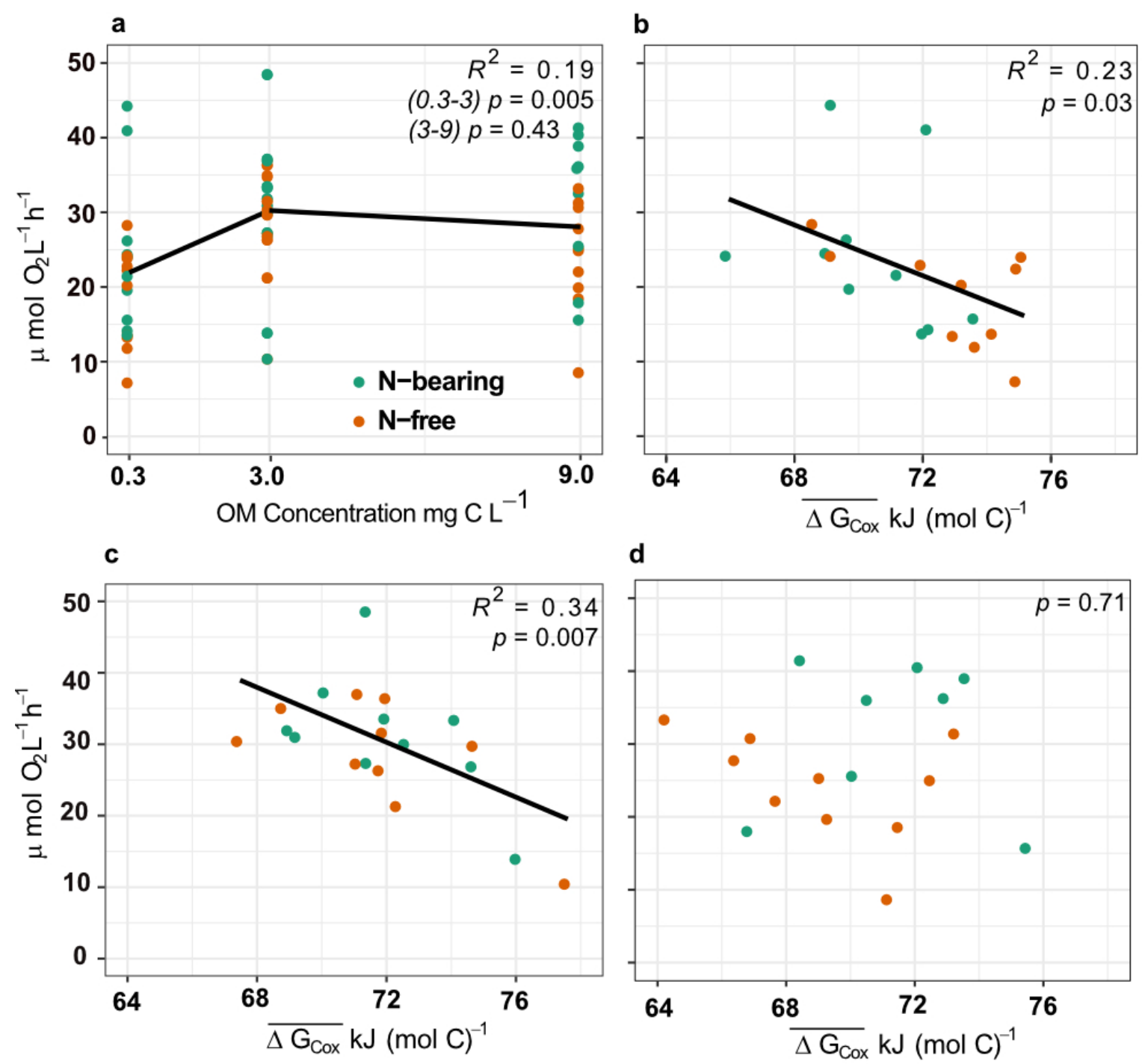

406 Fig. 1 Aerobic respiration rates in microcosms and its relationship with $\overline{\Delta \mathrm{G}^{\circ} \mathrm{Cox}}$. (a) Respiration 407 rates were higher in microcosms amended with $3 \mathrm{mg} \mathrm{C} \mathrm{L}^{-1}$ vs. $0.3 \mathrm{mg} \mathrm{C} \mathrm{L}^{-1}$, while microcosms 408 receiving $3 \mathrm{mg} \mathrm{C} \mathrm{L}^{-1}$ and $9 \mathrm{C} \mathrm{mg} \mathrm{L}^{-1}$ had similar respiration rates, indicating carbon limitation at 409 low concentrations of amended OM that was alleviated with increasing OM addition. In 410 microcosms with $\mathrm{OM}$ added at (b) $0.3 \mathrm{C} \mathrm{mg} \mathrm{L}^{-1}$ and (c) $3 \mathrm{mg} \mathrm{C} \mathrm{L}^{-1}, \overline{\Delta \mathrm{G}^{\circ} \mathrm{Cox}}$ shows a negative 411 relationship with respiration, while microcosms with (d) $9 \mathrm{mg} \mathrm{C} \mathrm{L}^{-1}$ amendments show no 412 relationship between OM thermodynamics and respiration rates. 

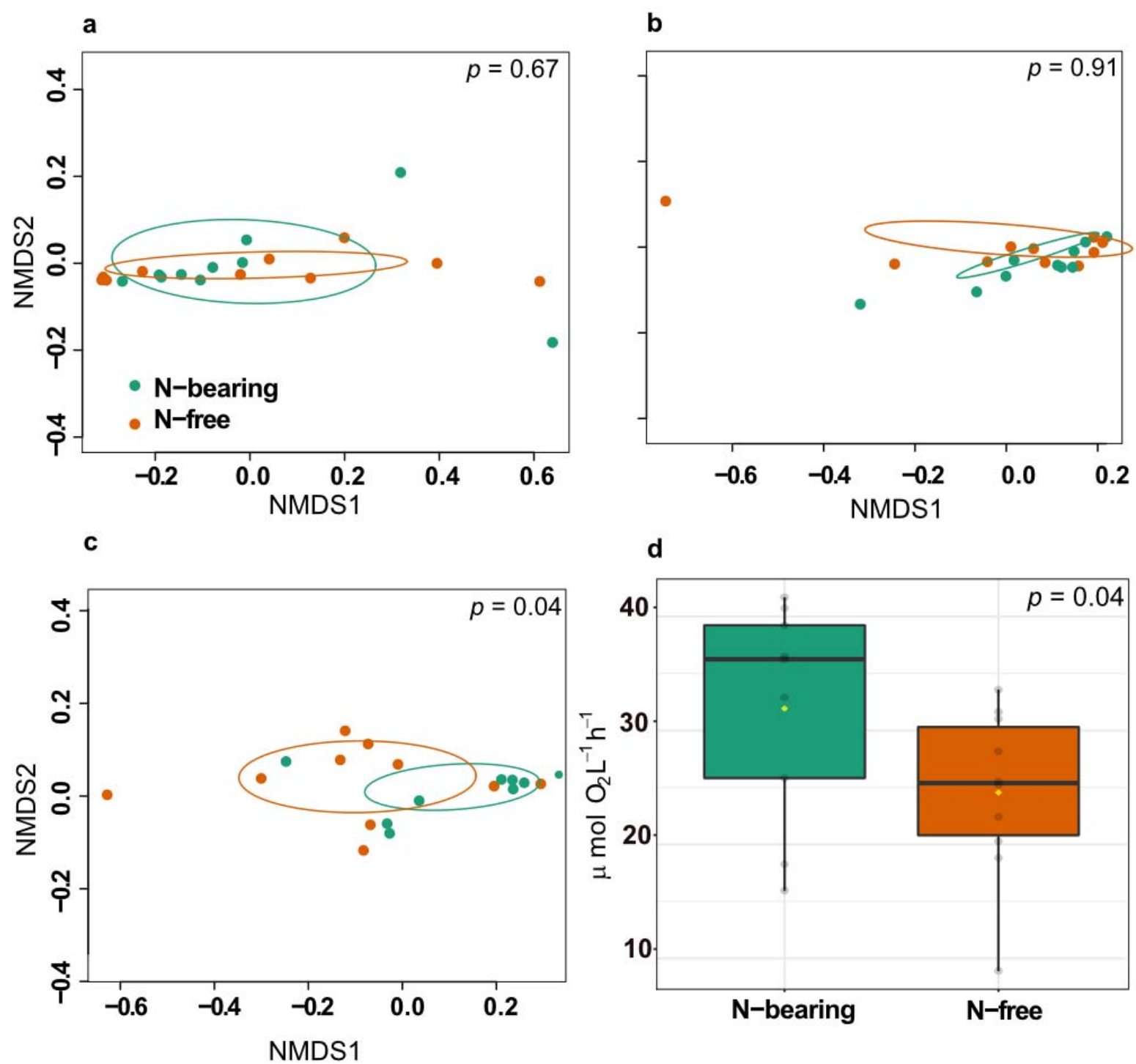

414 Fig. 2 Biochemical transformations between N-bearing and N-free OM amendments and its link with respiration rates. Non-metric multidimensional scaling (NMDS) plots of microcosms receiving low $\mathrm{OM}$ concentrations (a) $0.3 \mathrm{mg} \mathrm{C} \mathrm{L}^{-1}$ and (b) $3 \mathrm{mg} \mathrm{C} \mathrm{L}^{-1}$ showed no difference in biochemical transformation profiles between $\mathrm{N}$-bearing and $\mathrm{N}$-free amendments. In contrast, microcosms receiving high $\mathrm{OM}$ concentrations (c) $9 \mathrm{mg} \mathrm{C} \mathrm{L}^{-1}$ had significantly different biochemical transformation profiles between $\mathrm{N}$-bearing and $\mathrm{N}$-free amendments. (d) Microcosms amended with $\mathrm{N}$-bearing $\mathrm{OM}$ at $9 \mathrm{mg} \mathrm{C} \mathrm{L}^{-1}$ also showed enhanced respiration vs. those receiving $\mathrm{N}$-free $\mathrm{OM}$ at the same concentration. In contrary, respiration rates were not statistically different between $\mathrm{N}$-bearing and $\mathrm{N}$-free microcosms receiving low $\mathrm{OM}\left(0.3\right.$ and $\left.3 \mathrm{mg} \mathrm{C} \mathrm{L}{ }^{-1}\right)$. Colors in all panels indicate $\mathrm{N}$-bearing (teal) and $\mathrm{N}$-free (orange) $\mathrm{OM}$ amendments. $P$-values in (a-c) were derived from PERMANOVAs, and the $p$-value in (d) was calculated using a one-sided Mann425 Whitney U test. 


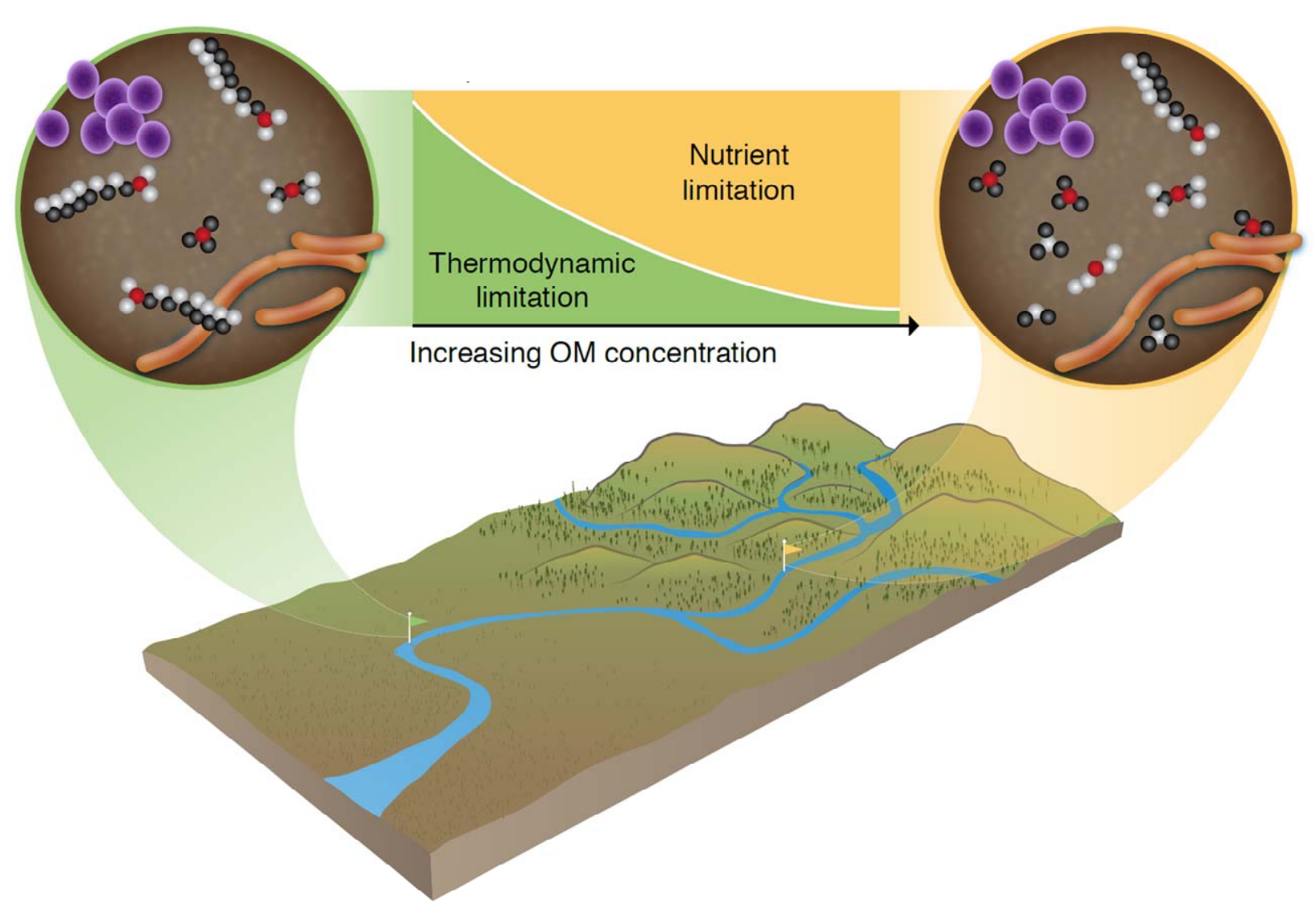

427 Fig. 3 Conceptualization of thermodynamic and nutrient regulations on aerobic respiration. We 428 propose a new conceptual model in which thermodynamic and nutrient limitations dually control aerobic respirations. We suggest that thermodynamic properties of OM govern aerobic 430 respiration rates in ecosystems with low carbon to nutrient ratios. When OM concentration reaches a threshold, thermodynamic controls do not persist, and nutrient availability, particularly

$432 \mathrm{~N}$ regulate respiration. This work highlights a structural gap in aquatic biogeochemical models 433 and challenges long-held beliefs about aerobic metabolism being solely governed by reaction 434 kinetics. This new paradigm provides a link between OM chemistry and biogeochemical rates 435 with direct avenues for model incorporation, where OM chemistry regulates OM oxidation 436 through its thermodynamic properties until OM concentrations are sufficient to induce nutrient 437 limitations. 